\title{
THE VALUE OF A SCIENTIFIC OUT- LOOK TO THE WORKER IN VENEREAL DISEASES *
}

By Col. L. W. HARRISON, D.S.O., M.B., Ch.B., F.R.C.P.E.

My choice of a subject for this address springs from a desire to see a closer harmony between the clinician and the laboratory worker, and a more scientific habit of thought on the part of clinicians practising in our branch of medicine.

In the course of my work, which brings me into contact with many specialists in venereal diseases, I have formed the opinion, which I would be glad to have good grounds for changing, that many clinicians work too much on empirical lines. They are content to follow along paths recommended by some enterprising author without any very clear idea of the principles which should govern their line of action.

A new situation, created, for example, by abnormal behaviour of a patient's symptoms, drives them to a book, not to discover the pathological processes underlying this abnormal behaviour, but what some author did in a like situation.

Often, again, I find clinicians and pathologists working in watertight compartments and not a little mutual suspicion between two classes of worker whose close co-operation is essential to progress. As an example, you know that not a little criticism has been levelled at the reliability of the serum tests of syphilis. I think that much of this criticism springs from a lack of knowledge, on the part of many clinicians, of the scientific principles and technique of the tests and consequent inability to understand the point of view of the pathologist. Often enough I have heard clinicians criticise particular results as contrary to the clinical findings when it was clear to any one with a knowledge of the tests in question that the pathologist most probably never intended the interpretation of his report which had been made of it by the com-

* Presidential Address to the M.S.S.V.D., Jan. 23rd, r925. 


\section{BRITISH JOURNAL OF VENEREAL DISEASES}

plaining clinician. A good example of this is the reaction which is often, too often I think, described by the pathologist as "weakly positive" and by many others as "doubtful." A clinician who has not taken the trouble to understand the test receives a report that a specimen has given a weakly positive reaction. If he has a suspicion that the patient is suffering from syphilis, he seizes on the word "positive" in the report and uses it as his justification for making a diagnosis of syphilis. Not infrequently, he thereby inflicts on a non-syphilitic patient a considerable amount of unnecessary mental torture. Or such a clinician, finding the pathologist's report not entirely in agreement with his views, sends another specimen from the same patient and may then receive a report that the result is negative. Often enough I have heard it asked, what trust can be put in tests which at such short intervals give with the same serum at one time positive and at another negative results? Yet a little knowledge of the technique and a little conversation with the pathologist would prevent his acceptance of a "weakly positive" report as justifying anything more than a suspicion and would also make it clear to the clinician that between the plainly syphilitic reaction and the clearly negative there is a zone into which some nonsyphilitic sera now and then wander. The pathologist knows all about it and has provided accordingly in his standards. He never intended, by reporting a serum as "weakly positive," to convey more than a doubt, and he is not the least surprised to find the same serum a week later giving a negative reaction. If all clinicians had this knowledge, some of the atmosphere of suspicion would be dissipated. It is an atmosphere which I should greatly like to disappear, not only because it would prevent some disastrous mistakes, but because progress towards higher standards of diagnosis and treatment will not be made where the pathologist and clinician are not in the closest possible sympathy. The pathologist working in his watertight compartment loses the advantage in his serum tests of checks by which to gauge the correctness of his standards for his reagents, and he does not receive the stimulus to research on practical problems which the clinician could often give him.

These are only a few of the ways in which progress suffers, and I should like to show now how it could gain 


\section{THE VALUE OF A SCIENTIFIC OUTLOOK}

by the clinician's closer study of pathological processes and sympathy with laboratory work. I cannot do it better than by reminding you of a few of the ways in which laboratory work has advanced the arts of diagnosis and treatment in medicine generally and in our own branch of it particularly.

In the general field I will cite only one example, the most brilliant of all, which I think sufficient to show the value to medicine of a clinician with a scientific outlook. It was the scientific outlook of Lister, primarily a surgeon, which gave us antiseptic surgery. I venture to say that it was very largely the lack of a scientific outlook in the practising surgeons of the 'seventies and part of the 'eighties, which delayed the acceptance of listerian principles for so many years. Lister was an example of the happiest combination; a clinician who sought by his own laboratory researches to solve the problems which confronted him daily, and the result was the happiest. Pasteur knew much more about germs. Doubtless many surgeons were more brilliant craftsmen than Lister, but it was the combination of clinician and scientist which conferred the greatest benefit on humanity.

You will agree that our own branch of medicine owes more than most to laboratory research, and I need mention only a few examples. The arsenobenzol compounds are largely the product of pure research. The bismuth treatment owes its being to a surmise by a chemist, that, from its chemical structure, it should be anti-spirochætal. We owe to the laboratory the serum tests of syphilis and the discovery of the micro-organisms of syphilis and gonorrhœa. The histologist has shown us the pathological processes at work in both syphilis and gonorrhœa, and from them we have learnt much of our real problem in treatment, as well as something of the lines on which to solve the problem. The histologist has shown us intimately the toxic effects of our anti-syphilitic treatment, and the bio-chemist has indicated to us some of the ways in which those toxic effects may be avoided. These are only a few of the debts which we owe to the laboratory worker, and I can say without fear of contradiction that it has been the patients of those clinicians who have been quickest to understand the teaching of the laboratory result who have been the quickest to benefit.

I will turn now to another side of the question, the value 


\section{BRITISH JOURNAL OF VENEREAL DISEASES}

of a laboratory training to the clinician in the help which habits of thought developed in laboratory research affords him in solving his clinical problems. I speak of this with gratitude because I feel keenly the debt which I owe to the training in laboratory methods of attacking problems which I received for only too short a time from Sir Almroth Wright and later from my brother. The laboratory worker has the advantage over the clinician that his observations can be more exact; he obtains his results much more quickly, and wrong processes of thought are corrected sooner. In a word he learns more rapidly to think on lines which are logical. I venture to say that the same methods of thought are of the greatest value in clinical research, and many pitfalls would be avoided if they were adopted more extensively by clinicians. An example comes to my mind which I rather fear to quote, partly because it occurs on controversial ground and partly because, in doing so, I may trespass on the ground of those who follow me this evening by opening the debate on vaccine therapy. Even at this risk, in the hope that my pathologist friends will forgive me, I will cite it. You have read much against the vaccine therapy of gonorrhœa. As far as I can recollect, the attack has usually been based on observations that for a time the observer treated his cases with vaccines, and his impression was that they did no better than those treated without vaccine at some time before or after. Often, no attempt has been made to discover exactly if the cases treated with vaccines were under the same conditions as those not so treated. No exact computation has been made of the results as to complications and the lengths of time the patients continued to be infective and no thought has been given to the possibility of the particular vaccine which was employed being, whether from strains employed or methods of sterilisation, an indifferent immuniser. In a word, the observer generalises from his mere impression that vaccines are useless in the treatment of gonorrhœea. I leave it to the pathologists to say what would happen to them if they arrived at this, or any other, conclusion by such a method of research, if one can dignify it with such a name. 'Just as Lister's work was received coldly because so few would learn its underlying principles, so much which is discovered in the laboratory suffers from wrong application and wrong methods of investigation by the clinician. 


\section{THE VALUE OF A SCIENTIFIC OUTLOOK}

But I see a greater advantage than the dissipation of suspicion and the avoidance of pitfalls in clinical research which would follow a closer study by the clinician of the scientific principles involved in the diagnosis and treatment of venereal diseases, and it is in the partnership which would result between the clinician and the pathologist. The clinician who views clinical phenomena from the pathological standpoint develops ideas on methods by which the pathological process might be combated. He takes his ideas to the pathologist, and together they work out lines of research which are much more likely to be fruitful than if he puts his surmise to the test in some haphazard way which cannot afford any conclusion. How much faster both would progress to the benefit of humanity if they would learn something of the other's work and so understand its possibilities and limitations! I venture again to take an example from vaccine therapy. The pathologist makes up his vaccine from such strains as come to him. Every one knows that strains of microorganisms vary in their immunising power, but, without the clinician's help, the pathologist has little or no means of knowing whether he is putting a majority of good immunisers or the reverse into his vaccine, and there is little wonder that the clinician gains a bad impression. The clinician might help a little at any rate by his observation of the immunising powers of different strains on the patients who provided them. At present he commonly does little or nothing but receive the vaccine and test it on a few patients. If the results are not magical, he remains for ever after sceptical of the value of vaccines. The two working together could at least work out the problem of getting the best out of this form of treatment in a way which they never could without collaboration.

I fear I have presented my argument feebly. I am conscious that it requires a power of expression which I sadly lack. I can only express again my sense of the help I have received in attacking the problems of our speciality from habits of thought which were acquired in the laboratory. 